\title{
Stimulasi Bermain Bercerita Metode Flanel Meningkatkan Sosialisasi Pada Anak Usia Prasekolah
}

\author{
Hindyah Ike Suhariati
}

\begin{abstract}
Socialization is an ability that pre-school children must have in order to build good interaction with their friends in school. In fact $70 \%$ of pre-school children yet unable to make socialization in school. The purpose of this study is explaining the influence of flannel story telling play stimulation method to the socialization of pre school children. The design of this study is Quasi Experiment. All of the pre-school children that experiencing lack of socialization in TK. Dharma Wanita Persatuan RSJ Dr. Radjiman Wediodiningrat Lawang become the population. Non Randomise Sampling method is used, with 32 respondent, 16 children used as treatment group and 16 others as the control group. The independent variable was flannel story telling play stimulation method and the dependent variable was the socialization. Data was analized by Wilcoxon Sign Rank test and Mann-Whitney test with significance rate 95\% $(\alpha=0,05)$. The result showed that flannel story telling play stimulation method influences the pre-school childrens socialization improvement $(p=0,000)$, playing activity according to the curriculum didn't improve the pre-school children socialization significantly $(p=0,157)$, there are difference between control group and after treatment group socialization with Mann-Whitney test ( $\mathrm{p}=$ 0,004). Flannel story telling play stimulation method could improve socialization ability of pre-school children significantly. This playing activity can be used as the pediatric nursing care cast, to treat children with socialization problems.
\end{abstract}

Keywords : Flannel playing method, Socialization, pre-school

\section{Pendahuluan}

Kemampuan bersosialisasi harus sudah dicapai pada anak usia pra sekolah, karena semakin cepat bersosialisasi anak akan mampu beriteraksi dengan temannya di sekolah, anak akan lebih percaya diri, dalam proses pembelajaran anak bisa mengembangkan perilaku positif, lebih nyaman bersekolah dan dapat mengeluarkan kemampuannya serta tumbuh dan berkembang secara optimal. Tetapi kenyataannya anak usia prasekolah belum bisa bersosialisasi di sekolah, hal ini terbukti masih banyaknya anak - anak yang tidak mau bergaul dengan temannya. Ketidakmampuan bersosialisasi pada anak prasekolah akan berdampak pada anak yaitu anak menjadi tidak percaya diri sehingga akan berpengaruh pada pertumbuhan dan perkembangan anak (Junetty, 2010). Berdasarkan pengamatan peneliti dalam hasil wawancara dengan kepala sekolah taman kanak - kanak Dharma Wanita
Persatuan RSJ Dr. Radjiman Wediodiningrat Lawang diketahui bahwa masih banyak $(70 \%)$ murid - murid yang belum bisa bersosialisasi dengan baik di sekolah. Hal ini terbukti banyak anak anak yang tidak mau ditinggal oleh ibunya, takut bergaul dengan temannya, dan hanya diam bila di tanya / tidak mau menjawab pertanyaan dari guru.

Kemampuan bersosialisasi diawali dengan anak mulai mengenal teman lalu berkembang dengan menjalin hubungan pertemanan, tetapi lingkupnya masih terbatas yang memiliki kesamaan tertentu, misal : rumahnya masih di satu lingkungan, sama - sama satu sekolah atau mempunyai mainan yang sama Di taman kanak - kanak permainannya sudah berkembang sesuai dengan tahapan perkembangan, tetapi kenyataannya anak - anak di suruh bermain sendiri oleh gurunya dan tidak diberikan stimulasi maupun pendampingan. 
Bercerita dengan flanel dapat memunculkan beberapa indikator aspek perkembangan, salah satunya adalah perkembangan interpersonal yang terlihat saat anak berinteraksi dan berani bertanya jawab dengan guru ataupun sesama temannya, sehingga membantu anak mempelajari cara bersosialisasi dengan anak dan orang dewasa lain serta cara menjalin hubungan baik dengan guru (Yuliani, 2010 ). Bercerita dengan flanel merupakan kegiatan bercerita menggunakan celemek flanel dan boneka laminating yang bertujuan untuk mengembangkan sosialisasi anak, berupa kegiatan bermain dimana guru/perawat memulai awal sebuah cerita dan setiap anak menambahkan cerita selanjutnya (Yuliani, 2010). Namun adanya pengaruh stimulasi bermain bercerita dengan flanel terhadap sosialisasi pada anak usia pra sekolah belum dapat dijelaskan. Tujuan penelitian ini menjelaskan pengaruh stimulasi bermain bercerita metode flanel terhadap sosialisasi pada anak usia prasekolah.

\section{Metode Penelitian}

Desain dalam penelitian ini adalah Quasi Experiment (Pre and Post test nonequivalent control group ) dimana dalam penelitian ini terdapat dua kelompok sampel yaitu kelompok perlakuan dan kelompok control. Populasi terjangkau adalah seluruh anak usia pra sekolah di TK Dharma Wanita Persatuan RSJ Dr Radjiman Wediodiningrat Lawang kabupaten Malang Jawa Timur yang mengalami ketidakmampuan dalam bersosialisasi. Jumlah populasi penelitian ini sebanyak 45 anak yang berasal kelas $\mathrm{A}$ sebanyak 25 orang, kelas B 20 orang. Besar sampel pada penelitian ini dari masing-masing kelas adalah 8 anak, 8 anak untuk kelompok perlakuan dari kelas A1 dan 8 anak untuk kelompok kontrol dari kelas A2, 8 anak untuk kelompok perlakuan dari kelas B1 dan 8 anak untuk kelompok kontrol dari kelas B2, seluruh subyek penelitian adalah 16 anak (kelompok perlakuan) +16 anak kelompok kontrol) $=32$ anak. Teknik pengambilan sampel yang digunakan peneliti adalah Non Randomise Sampling. Variabel Independen dalam penelitian ini adalah stimulasi bermain bercerita metode flanel. Penelitian dilakukan di TK Dharma Wanita Persatuan RSJ Dr Radjiman Wediodiningrat Lawang Kabupaten Malang Jawa Timur. Penelitian dilakukan pada tanggal 1 Maret sampai 26 Maret 2015. Analisis data berpasangan (pre and post test) pada variabel sosialisasi digunakan uji Wilcoxon sign rank test. Uji Mann Whitney Test untuk menguji perbedaan sosialisasi pada kelompok kontrol dan kelompok perlakuan setelah pemberian perlakuan. Software yang digunakan untuk uji statistik adalah SPSS 18.0 for windows. Jika hasil uji statistik didapatkan $\mathrm{p}<0,05$ maka $\mathrm{H} 1$ diterima artinya hipotesis penelitian diterima.

\section{Hasil Dan Pembahasan \\ Karakteristik Data Umum}

1) Jenis Kelamin

Tabel 1 Distribusi jenis kelamin responden di TK Dharma Wanita RSJ Dr. Radjiman Wediodiningrat Lawang Maret 2015

\begin{tabular}{lcccc}
\hline \multirow{2}{*}{$\begin{array}{c}\text { Jenis } \\
\text { Kelamin }\end{array}$} & \multicolumn{2}{c}{$\begin{array}{c}\text { Kelompok } \\
\text { Kontrol }\end{array}$} & \multicolumn{2}{c}{$\begin{array}{c}\text { Kelompok } \\
\text { Perlakuan }\end{array}$} \\
\cline { 2 - 5 } & $\sum$ & $\%$ & $\sum$ & $\%$ \\
\hline Laki-laki & 8 & $50 \%$ & 5 & $31,2 \%$ \\
Perempuan & 8 & $50 \%$ & 11 & $68,8 \%$ \\
\hline Jumlah & 16 & $100 \%$ & 16 & $100 \%$ \\
\hline
\end{tabular}

2) Umur

Tabel 2 Distribusi umur responden di TK Dharma Wanita RSJ Dr. Radjiman Wediodiningrat Lawang Maret 2015

\begin{tabular}{lcccc}
\hline \multirow{2}{*}{ Umur } & \multicolumn{2}{c}{$\begin{array}{c}\text { Kelompok } \\
\text { Kontrol }\end{array}$} & \multicolumn{2}{c}{$\begin{array}{c}\text { Kelompok } \\
\text { Perlakuan }\end{array}$} \\
\cline { 2 - 5 } & $\sum$ & $\%$ & $\sum$ & $\%$ \\
\hline 4 Tahun & 2 & $12,4 \%$ & 2 & $12,4 \%$ \\
5 Tahun & 7 & $43,8 \%$ & 11 & $68,8 \%$ \\
6 Tahun & 7 & $43,8 \%$ & 3 & $18,8 \%$ \\
\hline Jumlah & 16 & $100 \%$ & 16 & $100 \%$ \\
\hline
\end{tabular}


3) Posisi Anak Dalam Keluarga

Tabel 3 Distribusi Posisi anak dalam keluarga responden di TK Dharma Wanita RSJ Dr. Radjiman Wediodiningrat Lawang Maret 2015

\begin{tabular}{lcccc}
\hline $\begin{array}{c}\text { Posisi } \\
\text { Anak } \\
\text { Dalam }\end{array}$ & \multicolumn{2}{c}{$\begin{array}{c}\text { Kelompok } \\
\text { Kontrol }\end{array}$} & \multicolumn{2}{c}{$\begin{array}{c}\text { Kelompok } \\
\text { Perlakuan }\end{array}$} \\
\cline { 2 - 5 } Keluarga & $\sum$ & $\%$ & $\sum$ & $\%$ \\
\hline Pertama & 11 & $68,8 \%$ & 9 & $56,3 \%$ \\
Kedua & 4 & $25 \%$ & 6 & $37,5 \%$ \\
Ketiga & 1 & $6,2 \%$ & 1 & $6,2 \%$ \\
\hline Jumlah & 16 & $100 \%$ & 16 & $100 \%$ \\
\hline
\end{tabular}

4) Jumlah Anak

Tabel 4 Distribusi jumlah anak responden di TK Dharma Wanita RSJ Dr. Radjiman Wediodiningrat Lawang Maret 2015

\begin{tabular}{lcccc}
\hline $\begin{array}{c}\text { Jumlah } \\
\text { Anak }\end{array}$ & \multicolumn{2}{c}{$\begin{array}{c}\text { Kelompok } \\
\text { Kontrol }\end{array}$} & \multicolumn{2}{c}{$\begin{array}{c}\text { Kelompok } \\
\text { Perlakuan }\end{array}$} \\
\cline { 2 - 5 } & $\sum$ & $\%$ & $\sum$ & $\%$ \\
\hline Satu & 2 & $12,4 \%$ & 1 & $6,2 \%$ \\
Dua & 11 & $68,8 \%$ & 10 & $62,5 \%$ \\
Tiga & 3 & $18,8 \%$ & 5 & $31,3 \%$ \\
\hline Jumlah & 16 & $100 \%$ & 16 & $100 \%$ \\
\hline
\end{tabular}

5) Pendidikan Ortu

Tabel 5 Distribusi pendidikan ortu responden di TK Dharma Wanita RSJ Dr. Radjiman Wediodiningrat Lawang Maret 2015

\begin{tabular}{lcccc}
\hline $\begin{array}{c}\text { Pendidikan } \\
\text { Ortu }\end{array}$ & $\begin{array}{c}\text { Kelompok } \\
\text { Kontrol }\end{array}$ & \multicolumn{2}{c}{$\begin{array}{c}\text { Kelompok } \\
\text { Perlakuan }\end{array}$} \\
\cline { 2 - 5 } & $\sum$ & $\%$ & $\sum$ & $\%$ \\
\hline SMP & 3 & $18,8 \%$ & 3 & $18,8 \%$ \\
SMA & 11 & $68,8 \%$ & 11 & $68,8 \%$ \\
D3 & 1 & $6,2 \%$ & 2 & $12,4 \%$ \\
S1 & 1 & $6,2 \%$ & 0 & $0 \%$ \\
\hline Jumlah & 16 & $100 \%$ & 16 & $100 \%$ \\
\hline
\end{tabular}

6) Pekerjaan Ortu

Tabel 6 Distribusi pekerjaan ortu responden di TK Dharma Wanita RSJ Dr. Radjiman Wediodiningrat Lawang Maret 2015

\begin{tabular}{lcccc}
\hline \multirow{2}{*}{$\begin{array}{c}\text { Pekerjaan } \\
\text { Ortu }\end{array}$} & \multicolumn{2}{c}{$\begin{array}{c}\text { Kelompok } \\
\text { Kontrol }\end{array}$} & \multicolumn{2}{c}{$\begin{array}{c}\text { Kelompok } \\
\text { Perlakuan }\end{array}$} \\
\cline { 2 - 5 } & $\sum$ & \% & $\sum$ & $\%$ \\
\hline Swasta & 10 & $62,5 \%$ & 11 & $68,8 \%$ \\
PNS & 3 & $18,8 \%$ & 2 & $12,5 \%$ \\
CS & 1 & $6,2 \%$ & 2 & $12,5 \%$ \\
Tani & 1 & $6,3 \%$ & 0 & $0 \%$ \\
Buruh & 1 & $6,2 \%$ & 0 & $0 \%$ \\
Pelaut & 0 & $0 \%$ & 1 & $6,2 \%$ \\
\hline Jumlah & 16 & $100 \%$ & 16 & $100 \%$ \\
\hline
\end{tabular}

7) Kemampuan Berkomunikasi Anak Di Rumah

Tabel 8 Distribusi kemampuan berkomunikasi responden di TK Dharma Wanita RSJ Dr. Radjiman Wediodiningrat Lawang Maret 2015

\begin{tabular}{lcccc}
\hline $\begin{array}{c}\text { Kemampuan } \\
\text { Berkomunikasi } \\
\text { Anak }\end{array}$ & $\begin{array}{c}\text { Kelompok } \\
\text { Kontrol }\end{array}$ & \multicolumn{2}{c}{$\begin{array}{c}\text { Kelompok } \\
\text { Perlakuan }\end{array}$} \\
\cline { 2 - 5 } & $\sum$ & $\%$ & $\sum$ & $\%$ \\
\hline Ya & 9 & $56,3 \%$ & 9 & $56,3 \%$ \\
\hline Tidak & 7 & $43,7 \%$ & 7 & $43,7 \%$ \\
\hline Jumlah & 16 & $100 \%$ & 16 & $100 \%$ \\
\hline
\end{tabular}

8) Gaya Pengasuhan

Tabel 9 Distribusi gaya pengasuhan responden di TK Dharma Wanita RSJ Dr. Radjiman Wediodiningrat Lawang Maret 2015

\begin{tabular}{lcccc}
\hline \multirow{2}{*}{$\begin{array}{c}\text { Gaya } \\
\text { Pengasuhan }\end{array}$} & \multicolumn{2}{c}{$\begin{array}{c}\text { Kelompok } \\
\text { Kontrol }\end{array}$} & \multicolumn{2}{c}{$\begin{array}{c}\text { Kelompok } \\
\text { Perlakuan }\end{array}$} \\
\cline { 2 - 5 } & $\sum$ & $\boldsymbol{\%}$ & $\sum$ & $\%$ \\
\hline Demokratis & 5 & $31,3 \%$ & 4 & $25 \%$ \\
\hline Permisif & 4 & $25 \%$ & 3 & $18,8 \%$ \\
\hline Otoriter & 7 & $43,7 \%$ & 9 & $56,2 \%$ \\
\hline Jumlah & 16 & $100 \%$ & 16 & $100 \%$ \\
\hline
\end{tabular}

\section{Penyajian Hasil Yang Diukur}

Hasil Penelitian Sosialisasi Anak Usia Pra Sekolah Kelompok Kontrol Dan Kelompok Perlakuan

Tabel 10 Hasil Penelitian Sosialisasi Anak Usia Pra Sekolah Pada Kelompok kontrol Dan Kelompok Perlakuan di TK Dharma Wanita RSJ Dr. Radjiman Wediodiningrat Lawang Maret 2015

\begin{tabular}{|c|c|c|c|c|c|c|c|c|}
\hline \multirow{3}{*}{ Kategori } & \multicolumn{4}{|c|}{ Kelompok Kontrol } & \multicolumn{4}{|c|}{$\begin{array}{l}\text { Kelompok } \\
\text { Perlakuan }\end{array}$} \\
\hline & \multicolumn{2}{|c|}{ Pre Test } & \multicolumn{2}{|c|}{$\begin{array}{l}\text { Post } \\
\text { Test }\end{array}$} & \multicolumn{2}{|c|}{$\begin{array}{c}\text { Pre } \\
\text { Test }\end{array}$} & \multicolumn{2}{|c|}{$\begin{array}{l}\text { Post } \\
\text { Test } \\
\end{array}$} \\
\hline & $\sum$ & $\%$ & $\sum$ & $\%$ & $\sum$ & $\%$ & $\sum$ & $\%$ \\
\hline Baik & 0 & $0 \%$ & 0 & $\begin{array}{l}0 \\
\%\end{array}$ & 0 & $\begin{array}{l}0 \\
\%\end{array}$ & 7 & $\begin{array}{l}43, \\
7 \%\end{array}$ \\
\hline Cukup & 2 & $12,5 \%$ & 4 & $\begin{array}{l}25 \\
\%\end{array}$ & 4 & $\begin{array}{l}2 \\
5 \\
\%\end{array}$ & 9 & $\begin{array}{l}56, \\
2 \%\end{array}$ \\
\hline Kurang & 14 & $87,5 \%$ & 12 & $\begin{array}{l}75 \\
\%\end{array}$ & 12 & $\begin{array}{l}7 \\
5 \\
\%\end{array}$ & 0 & $0 \%$ \\
\hline Jumlah & 16 & $100 \%$ & 16 & $\begin{array}{c}10 \\
0 \\
\%\end{array}$ & 16 & $\begin{array}{l}1 \\
0 \\
0 \\
\%\end{array}$ & 16 & $\begin{array}{l}10 \\
0 \%\end{array}$ \\
\hline
\end{tabular}


Berdasarkan Tabel 10 di atas diketahui bahwa sosialisasi pada kelompok kontrol sebelum intervensi sebagian besar pada kategori kurang sebanyak 14 anak (87,5\%). Setelah intervensi sosialisasi pada kelompok kontrol pada kategori kurang sebanyak 12 anak $(75 \%)$.

\section{Perbedaan Sosialisasi pada Kelompok Perlakuan dan Kelompok Kontrol}

Tabel 11 Pebedaan Sosialisasi Anak Usia Pra Sekolah Pada Kelompok Perlakuan dan Kelompok Kontrol di TK Dharma Wanita RSJ Dr. Radjiman Wediodiningrat Lawang Maret 2015

\begin{tabular}{|c|c|c|c|c|c|c|}
\hline \multirow{2}{*}{$\begin{array}{c}\text { No } \\
\text { Respon } \\
\text { den }\end{array}$} & \multicolumn{2}{|c|}{ Kontrol } & \multicolumn{2}{|c|}{ Perlakuan } & \multicolumn{2}{|c|}{$\begin{array}{l}\text { Analisis } \\
\text { Posttest }\end{array}$} \\
\hline & $\begin{array}{l}\text { Pre } \\
\text { Test }\end{array}$ & $\begin{array}{l}\text { Post } \\
\text { Test }\end{array}$ & $\begin{array}{l}\text { Pre } \\
\text { Test }\end{array}$ & $\begin{array}{l}\text { Post } \\
\text { Test }\end{array}$ & $\begin{array}{l}\text { Kon } \\
\text { trol }\end{array}$ & $\begin{array}{l}\text { erla } \\
\text { zuan }\end{array}$ \\
\hline 1 & 9 & 10 & 10 & 27 & 10 & 27 \\
\hline 2 & 9 & 9 & 16 & 29 & 9 & 29 \\
\hline 3 & 9 & 9 & 9 & 19 & 9 & 19 \\
\hline 4 & 9 & 9 & 9 & 27 & 9 & 27 \\
\hline 5 & 9 & 10 & 9 & 19 & 10 & 19 \\
\hline 6 & 10 & 14 & 9 & 18 & 14 & 18 \\
\hline 7 & 9 & 10 & 14 & 29 & 10 & 29 \\
\hline 8 & 9 & 9 & 9 & 20 & 9 & 20 \\
\hline 9 & 16 & 20 & 10 & 19 & 20 & 19 \\
\hline 10 & 9 & 10 & 9 & 28 & 10 & 28 \\
\hline 11 & 9 & 9 & 16 & 30 & 9 & 30 \\
\hline 12 & 10 & 15 & 9 & 18 & 15 & 18 \\
\hline 13 & 9 & 9 & 9 & 19 & 9 & 19 \\
\hline 14 & 9 & 9 & 9 & 18 & 9 & 18 \\
\hline 15 & 9 & 10 & 9 & 20 & 10 & 20 \\
\hline 16 & 14 & 17 & 16 & 29 & 17 & 29 \\
\hline $\begin{array}{l}\text { Hasil } \\
\text { Perhitu } \\
\text { ngan } \\
\text { Stastika }\end{array}$ & $\begin{array}{l}\text { Wilcoxon } \\
\text { Signed } \\
\text { Test } \\
P=0,007\end{array}$ & Ranks & $\begin{array}{l}\text { Wilco } \\
\text { Signe } \\
\text { Test } \\
P=0\end{array}$ & Ranks & $\begin{array}{l}\text { Mar } \\
\text { Whi } \\
\text { Test } \\
P \\
0,00\end{array}$ & $\begin{array}{l}n- \\
\text { ney }\end{array}$ \\
\hline
\end{tabular}

Berdasarkan tabel 11 di atas menunjukkan dengan uji Wilcoxon Signed Ranks Test soaialisasi sebelum dan setelah intervensi pada kelompok kontrol didapatkan nilai $p=0,007$, karena nilai $\mathrm{p}$ $>0,05$ maka $\mathrm{H} 0$ diterima artinya tidak ada pengaruh kegiatan bermain sesuai kurikulum di sekolah terhadap sosialisasi pada anak usia prasekolah.

. Hasil analisis data penelitian dengan uji Wilcoxon Signed Ranks Test sosialisasi sebelum dan setelah intervensi didapatkan nilai $p=0,000$, karena nilai $\mathrm{p}$ $<0,05$ yang berarti H0 ditolak artinya ada pengaruh stimulasi bermain bercerita metode flanel terhadap sosialisasi pada anak usia pra sekolah.

Hasil pretest dan posttest pada kelompok perlakuan dan kelompok kontrol kemudian dibandingkan dengan uji statistik nonparametrik Mann Whitney test. Didapatkan nilai sebelum intervensi $p$ $=0,382$,berarti $\mathrm{H} 0$ diterima artinya tidak ada perbedaan sosialisasi antara kelompok perlakuan dan kelompok kontrol sebelum intervensi. Hasil uji statistik Mann Whitney setelah intervensi didapatkan nilai $\mathrm{p}=0,000$, berarti $\mathrm{H} 0$ ditolak artinya ada perbedaan sosialisasi antara kelompok perlakuan dan kelompok kontrol setelah intervensi.

Secara statistik ada pebedaan yang sangat bermakna soasialisasi kelompok perlakuan antara sebelum intervensi dan setelah intervensi $(p=0,000)$. Nilai signifikansi ini menunjukkan bahwa ada pengaruh stimulasi bermain bercerita metode flanel terhadap soasialisasi anak usia pra sekolah. Stimulasi bermain bercerita metode flanel meningkatkan kemampuan bersosialisasi yang terlihat saat anak berinteraksi dan berani bertanya jawab dengan guru dan perawat ataupun dengan sesama temannya, anak dapat menghubungkan isi boneka laminating "Aku dan Sekolahku", dapat merangakai kata untuk mengajukan pertanyaan, dapat menjadi pendengar yang baik dan berkonsentrasi sampai guru/perawat selesai bercerita.

Teori Piaget menjelaskan cara berpikir, memahami dan belajar. Piaget meyakini bahwa kecerdasan adalah proses kognitif atau mental yang digunakan anak untuk memperoleh pengetahuan. Kecerdasan adalah mengetahui dan melibatkan penggunaan operasi mental, yang berkembang sebagai akibat dari tindakan mental dan fisik di lingkungan sekitar. Piaget juga berpikir bahwa kecerdasan memiliki dasar biologis, 
seluruh organisme termasuk manusia, beradaptasi terhadap lingkungannya. Piaget menerapkan konsep adaptasi hingga tingkat pikiran, dan menggunakannya untuk menjelaskan cara anak merubah pemikirannya dan berkembang secara kognitif sebagai hasil dari pergaulan dengan orang tua, guru, kerabat, teman dan lingkungan. Lewat interaksi dengan lingkungan, anak - anak mengorganisir sensasi dan pengalaman dan otak mereka berkembang. Permainan adalah cara utama anak untuk terlibat secara aktif dengan lingkungannya dan untuk berpikir dan belajar. Bermain dengan anak - anak lain juga memudahkan anak untuk mengembangkan makna hubungan sosial (Morrison, 2012).

Stimulasi bermain metode flanel merupakan salah satu bentuk rangsangan dari lingkungan agar anak berpikir, memahami dan belajar berinteraksi dengan teman, guru dan juga perawat. Dengan interaksi yang dilakukan secara terus menerus anak akan mengembangkan makna hubungan sosial, sehingga anak mampu melakukan sosialisasi di sekolah.

\section{Kesimpulan}

1) Stimulasi bermain bercerita metode flanel meningkatan sosialisasi pada anak usia pra sekolah di TK Dharma Wanita Persatuan RSJ Dr Radjiman Wediodiningrat Lawang (kelompok perlakuan)

2) Kegiatan bermain sesuai kurikulum di sekolah meningkatkan sosialisasi pada anak usia prasekolah TK Dharma Wanita Persatuan RSJ Dr Radjiman Wediodiningrat Lawang (kelompok kontrol)

3) Peningkatan sosialisasi dengan stimulasi bermain metode flanel lebih tinggi dibandingkan dengan kegiatan bermain sesuai kurikulum di sekolah.
Saran

\section{Bagi Institusi Pendidikan TK}

1. Stimulasi bermain bercerita metode flanel dapat dijadikan untuk panduan penyusunan kurikulum di Taman Kanak - Kanak

2. Stimulasi bermain bercerita metode flanel sebaiknya dilakukan tiga kali dalam seminggu

\section{Bagi Peneliti Selanjutnya}

1) Perlu dilakukan penelitian lebih lanjut efektifitas stimulasi bermain bercerita metode flanel pada anak yang baru masuk sekolah dan pada pembelajaran satu semester.

\section{Daftar Pustaka}

Arikunto, S. (2006). Prosedur Penelitian Suatu Pendekatan Praktek. Jakarta : Rineka Cipta.

Dahlan, S. (2009). Besar Sampel Dan Cara Pengambilan Sampel. Jakarta : Salemba Medika.

Dharma, K. (2011). Metodologi Penelitian Keperawatan. Jakarta : CV Trans Info Media.

Carter A, Gowan MJ, Jones SM, Little TD. (2003). The Infant - Toddler Social and Emotional Assessment (ITSEA) : Factor Structure, Reliability, and Validity. Journal Of Abnormal Child Psychology, Vol. 31, No. 5, pp 495 - 514. Diakses 15 Februari 2015 (http://Springerlink.com/)

Cunningham JM, Booth RA Jr. (2008). Practice With Children and Their Families: A Specialty of Clinical Social Work. Child Adolesc Social Work Journal, 25:347 - 365. Diakses $15 \quad$ Februari 2015 (http://Springerlink.com/)

Han Susan S, Catron T, Weiss B, Marciel KK. (2004). A TeacherConsultation Approach to Social 
Skill Training for PreKindergarten Children : Treatment Model and Short-Term Outcome Effects. Journal of Abnormal Child Psychology, Vol. 33, No. 6, pp 681 - 693. Diakses 15 Februari 2015 (http://Springerlink.com/)

Hidayat, A. (2005). Pengantar Ilmu Keperawatan Anak 1. Jakarta : Salemba Medika.

Hidayat, A. (2006). Pengantar Kebutuhan Dasar Manusia. Jakarta : Salemba Medika.

Hurlock, Elizabeth B. (1999). Psikologi Perkembangan Suatu Pendekatan Sepanjang Rentang Kehidupan edisi 5. Jakarta : Erlangga.

Hurlock, Elizabeth B. (2005). Perkembangan Anak Jilid 1 Edisi 6. Jakarta : Erlangga.

Kawabata Y, Crick NR, Hamaguchi Y. (2010). Forms of Aggression, Social - Psychological Adjustment, and Peer Victimization in a Japanese Sample : The Moderating Role of Positive and Negative Friendship Quality. Journal Abnorm Child Psychology, 38:471 - 484. Diakses $15 \quad$ Februari 2015 (http://Springerlink.com/)

Lavalle KL, Bierman KL, Nix RL, and The Conduct Problems Prevention Research Group. (2005). The Impact of First - Grade "Friendship Group" Experiences on Child Social Outcomes in The Fast Track program. Journal of Abnormal Child Psychology, Vol. 33, No. 3 pp.307 - 324. Diakses $15 \quad$ Februari 2015 (http://Springerlink.com/)
Morrison, G. (2012). Dasar - Dasar Pendidikan Anak Usia Dini. Jakarta : PT Indeks.

Mulyadi, Seto. (2005). Tumbuh Kembang Anak. Jakarta : EGC.

Muscari, Mary E. (2005). Panduan Belajar Keperawatan Pediatric. Jakarta : EGC.

Ngastiyah. (2005). Perawatn Anak Sakit. Jakarta : EGC.

Nursalam. (2005). Asuhan Keperawatan Bayi Dan Anak. Jakarta : Salemba Medika.

Nursalam. (2008). Konsep Dan Penerapan Metodologi Penelitian Ilmu Keperawatan. Jakarta : Salemba Medika.

Owens EB, Shaw DS. (2003). Predicting Growth Curves of Externalizing Behavior Across the Preschool Years. Journal Of Abnormal Child Psychology, Vol. 31, No. 6, pp. 575 - 590. Diakses 15 Februari 2015(http://Springerlink.com/)

Pillitteri, Adele. (1999). Child Health Nursing Care Of The Child And Family. Philadelphia : Lippincott.

Rasmun. (2004). Stress, Koping Dan Adaptasi. Jakarta : CV Sagung Seto.

Sachrain, Rosa M. (1996). Prinsip Keperawatan Pediatric Edisi 2. Jakarta : EGC.

Santos AJ, Vaughn BE, Bost Kelly K. (2008). Specifying Social Structures in Preschool Classrooms : Descriptive and Functional Distinctions Between Affiliative Subgroups. Acta Ethol, 
11:101 -113. Diakses 15 Februari 2015 (http://Springerlink.com/)

Santrock JW. (2007). Perkembangan Anak. Jakarta : Erlangga.

Smeekens S, Walraven MR, Bakel HJ, et al. (2008). Profiles of competence and adaptation in preschoolers as to the quality of parent child interaction. 38:471-484. Diakses 19 Februari 2015 (http://scholar google.com/home.url)

Soetjiningsih. (1998). Tumbuh Kembang Anak. Jakarta : EGC

Suherman. (2000). Buku Saku Perkembangan Anak. Jakarta : EGC

Supartini, Yupi. (2000). Konsep Dasar Keperawatan Anak. Jakarta : EGC.
Supartini. (2004). Pertumbuhan dan Perkembangan Buah Hati. Jakarta : PT Alex Media Komputindo.

Tomey \& Alligood. (2002). Nursing Theorists Seventh Edition. Philadelphia : Mosby.

Whaley \& Wong. (1995). Nursing Care Of Infant \& Children Second Edition. St Louis : Mosby.

Wong, Donna L.(2004). Pedoman Klinis Keperawatan Pediatric Edisi 4. Jakarta : EGC

Wong, Donna L.(2009). Buku Ajar Keperawatan Pediatric Edisi 6. Jakarta : EGC

Yuliani, N. (2010). Bermain Kreatif Berbasis Kecerdasan Jamak. Jakarta : PT Indeks. 